\title{
LOS “PELELES": FRAUDES CONTRA LAS COMPAÑIIAS DE SEGUROS DE VIDA EN MÉXICO, 1902-1908
}

\author{
Diego Pulido Esteva \\ El Colegio de México
}

$\mathrm{F}$ ste artículo estudia una serie de estafas en contra de las principales compañías de seguros de vida que ofrecían sus servicios en México a comienzos del siglo xx. ${ }^{1}$ Dependiendo de la versión, las sumas de dichos fraudes se estimaron entre 100000 y 200000 pesos de la época. Si bien eran cantidades de dinero considerables, la atención se centró en la organización y el carácter inusitado de los hurtos.

En una carta anónima, The Equitable Life Insurance Company fue informada del procedimiento por medio del cual había sido engañada: en primer lugar, los defraudadores contrataron una póliza suplantando la identidad del asegurado, luego simularon la muerte de éste, tramitaron el certificado de defunción emitido por un médico y avalado en el registro civil

Fecha de recepción: 15 de enero de 2020

Fecha de aceptación: 1ㅇe mayo de 2020

1 Una versión preliminar de este texto fue presentada en el Seminario de Historia Sociocultural de la Transgresión. Agradezco las observaciones de Elisa Speckman y Martha Santillán -sus directoras, lo mismo que a Beatriz Alcubierre, Rocío Corona e Ignacio Ayala. Asimismo, agradezco el apoyo de Ámbar Espinosa de los Monteros en la revisión y reproducción de documentos. 
y, posteriormente, velaron y enterraron el supuesto cadáver con discreto pero protocolario cortejo. Cuando el fraude fue expuesto, se descubrió que el cuerpo dentro del féretro era en realidad un muñeco. Posteriormente, los beneficiarios de la póliza acudieron a las oficinas para reclamar la indemnización, lo cual habían conseguido en cuanto menos seis ocasiones.

Muy pronto denominado el "asunto de los peleles", dicha cadena de estafas permite analizar prácticas criminales todavía poco exploradas por la historia social del delito y la justicia tanto en México como en América Latina. ${ }^{2}$ Tras ser descubiertos, 18 individuos fueron detenidos y declarados formalmente presos para enfrentar un juicio ribeteado por el azoro, el escándalo y, en cierto grado, la impunidad. En este sentido, el caso invita a pensar históricamente ciertas formas de profesionalización del fraude durante una temporalidad ceñida a los fraudes y el proceso contra los presuntos responsables.

\section{EL “CHASCO” DE LOS PELELES}

Alrededor de las 11:00 de la mañana del 4 de marzo de 1902 fue exhumado un cuerpo en el Panteón Español con el propósito de satisfacer una denuncia interpuesta por la sucursal en la ciudad de México de La Equitativa, una prestigiosa compañía de seguros de vida con matriz en Nueva York. En esta querella, los representantes de la aseguradora habían mostrado la carta anónima ya mencionada, lo mismo que algunas pruebas para fundamentar sus sospechas sobre un posible fraude, razón por la cual era necesario certificar que los restos del propietario de la póliza se encontraban en el sepulcro. Tras examinar la denuncia

2 Para la legislación y justicia véase, en general, SPeckman, Crimen y castigo. Para casos de estafa: Piccato, "De otarios". Y para el Atlántico sudamericano véase Galeano, Criminosos viajantes. A nivel general es escasa la investigación histórica sobre fraudes y otros delitos financieros. Véase DRIEL, "Financial”, pp. 5-8. 
y las pruebas, el ministerio público determinó que debía exhumarse el cuerpo.

Ante la perplejidad del juez y del agente ministerial -acompañados por dos médicos legistas e igual número de periodistas-se constató que, en lugar de un cadáver humano, el cuerpo sepultado correspondía a un muñeco con rostro de cera realistamente confeccionado, con barba y bigote cuidadosamente recortados, ataviado con un elegante traje de pies a cabeza, pero con el torso y las piernas rellenos de trapos y aserrín. De inmediato fue apresado uno de los médicos presentes en la singular escena, pues éste había expedido el certificado de defunción del ahora hipotético difunto, mientras que se turnó una orden de aprehensión en contra de José Madiedo Viñas, beneficiario y hermano del titular de la póliza a nombre de Manuel, quien supuestamente había fallecido de pulmonía dos meses atrás y que debía estar dentro del ataúd. ${ }^{3}$

Aparentemente aislado, pasó poco tiempo para que otras compañías, en particular la New York y La Mutua, denunciaran sendos fraudes en su contra y cuyos realizadores habían repetido, casi en forma idéntica, el insólito procedimiento detallado en la carta y empleado por José Madiedo para engañarlas. Así comenzó la historia de "los peleles", conocida de esa forma en clara alusión a los maniquíes elaborados de paja o trozos de tela que fueron desenterrados en seis ocasiones distintas.

Si bien la misiva anónima dio pie a las pesquisas, declaraciones permitieron sumar sospechosos. La mayor parte de éstos fueron aprehendidos en la ciudad de México. De las primeras averiguaciones es posible construir, con ligeras discrepancias, una versión que ataba cada una de las estafas dentro de una suerte de plan maestro atribuido a los hermanos Ramón y Eduardo Balmori.

3 AGN, TSJDF, c. 137, exp. 27095, José Madiedo Viñas en apelación de sentencia por estafa frustrada. Segunda Sala (penal), 23 de septiembre de 1902. Véase también “Sensacional jurado por estafa de \$20000”, El Popular (21 ago. 1902). 
Como no fueron juzgados, carecemos de información general sobre ambos, salvo que el primero era propietario de una tienda de abarrotes en la esquina de la calle de las Moscas y Mixcalco, mientras que el segundo había trabajado como agente de seguros en la New York.

Para los declarantes, Ramón Balmori era "el director de todo el negocio", que comenzó con el cobro de la póliza de su difunta esposa. Todavía se encontraba con la salud frágil cuando José Madiedo le propuso asegurarla. Balmori aceptó y, en lugar de su mujer, presentó al agente de la Compañía de Seguros a una persona "plena en salud" en lugar de aquella "que día a día iba entregando su cuerpo a la fosa”. ${ }^{4}$ La señora Balmori había fallecido un mes antes de que su marido adquiriera una póliza por 10000 pesos. Con el certificado emitido por Félix Pérez, consiguieron asestar el primer golpe a La Mutua en la ciudad de México, entonces dirigida por Carlos Sommer.

Entusiasmado después de la referida estafa y de obtener 10000 pesos, Balmori propuso que José Madiedo hiciera de "pelele", quien aceptó asegurarse por la suma de 30000 pesos. ${ }^{5}$

${ }^{4}$ Mellado, "El extraño" y, del mismo autor, Belén, pp. 151-152.

${ }^{5}$ José Madiedo -de 32 años, originario de Villaviciosa, en Oviedo, y llegado a México en 1899- detalló su participación: en 1901 contrató una póliza por 20000 pesos con la Compañía de Seguros La Equitativa y designó a su hermano Manuel como beneficiario. Pagó dos meses y el 24 de enero del año siguiente se "dio por muerto" y fue enterrado en el Panteón Español. El doctor Félix Pérez trataba al supuesto difunto y extendió el certificado de defunción. Por su parte, Manuel Madiedo comenzó las gestiones para reclamar los 20000 pesos. En las "pruebas de muerte" que recabó la dirección de la compañía, el doctor Pérez aseguró que conocía al finado desde hacía dos años y que vio el cadáver antes que fuese sepultado. Sin embargo, la compañía se resistía a pagar y sospechaba que se le quería estafar. Todavía no efectuaba el pago cuando recibió un anónimo que aseguraba que José Madiedo no había muerto. Se integró el expediente y denunció el hecho ante el Juez $2^{\circ}$ de lo Criminal, Martín Mayora. Por su parte, Francisco puso todo su empeño en obtener los 20000 pesos del seguro. "Patrocinado" por Francisco Serralde, pretendió el embargo de la compañía, que se defendió alegando que esto no era por falta de 
Pagó la prima durante algunos meses y maduraron el plan a la perfección: confeccionarían un muñeco lo más parecido posible a Madiedo, quien desapareció en el populoso barrio de Mixcalco, corrió la noticia de su muerte, mientras que su hermano Manuel contrató un servicio funerario con todo y dolientes. El funeral se llevó a cabo y el "pobre muñeco" fue sepultado con sobria ceremonia en el Panteón Español. Una vez más solicitaron del doctor Pérez el certificado de defunción, con el cual pidieron de La Mutua los 30000 pesos del asegurado. Repartieron el dinero entre Celorio, Eguía, Balmori y los Madiedo. ${ }^{6}$

Al haber consumado con relativa facilidad la segunda estafa, se aventuraron a "operar en mayor escala". Según Madiedo, el negocio "entraba en auge" y, por medio de las gestiones de Balmori, aseguró a los cómplices en las diversas compañías que existían. Incluso sacó una póliza para el supuesto difunto José Madiedo, empleando para ello un nombre falso. La suma de esas pólizas ascendía a más de medio millón de pesos.

En adelante modificaron su estrategia. En algunos casos emplearon muñecos, pero en otros se hicieron pasar por benefactores y persuadieron a gente sin recursos de financiar el funeral y entierro de algún deudo. No se trataba de un patrocinio altruista, pues con habilidad lograron cambiar la identidad de los difuntos y redimir las respectivas pólizas. A propósito de esto, un matrimonio de personas sumamente pobres testificó que, cuando murió un amigo en su cuarto de vecindad, con dos pesos compraron el ataúd y no tenían para el entierro. Al cabo de unas horas llamaron a la puerta del "humilde hogar", y encontraron a un individuo vestido de negro a quien acompañaba una señora también enlutada. Les dijeron que vivían en Niño Perdido,

fondos, sino porque sospechaban que se trataba de un engaño: José Madiedo Viñas en apelación de sentencia por estafa frustrada. Segunda Sala (penal), 23 de septiembre de 1902, AGN, TSJDF, c. 137, exp. 27095, ff. 1-14, 29 y 35.

6 Emeterio Celorio en juicio de apelación por estafa. Segunda sala (penal), julio-agosto de 1902, AGN, TSJDF, c. 133, exp. 251407, ff. 42-48. 
eran acaudalados y por caridad auxiliaban a la gente humilde a enterrar sus cadáveres: se lo entregaron y ése sería el cuerpo que hicieron pasar por Vicente Cerezo. ${ }^{7}$

Otros tres féretros se exhumaron la mañana del 18 de junio de 1902 en el Panteón Dolores. Si bien los cuerpos debían corresponder a Jesús Yarto, Antonio Piña y Ponce de León, y Francisco García Méndez, el juez y secretario, junto con los peritos médicos Jacinto García y A. Maldonado y Morón, así como José R. Avilla, representante de la parte civil, descubrieron que el cuerpo de Yarto ocupaba la fosa 31226 de $4^{a}$ clase, y en su lugar se hallaba el de una mujer. El de Antonio Piña estaba en la fosa 6560 de $3^{a}$ clase, y en su lugar se hallaba un anciano (Ambrosio Macías, el vecino del testimonio ya mencionado); finalmente, en la fosa que debía ocupar García Méndez, se hallaba el cuerpo de un adulto desconocido de "clase baja". ${ }^{8}$

Antes de las exhumaciones, los planes de "los peleles” se habían consumado sin levantar sospechas. Ramón Balmori cerró su casa de comercio y regresó a España, mientras que Juan Rodríguez Zamora - hasta entonces agente en la policía Reservada- partió rumbo a La Habana. Cuando se descubrió el primer fraude y se pergeñaron las primeras versiones de lo ocurrido, varios periódicos afirmaron que no existía el delito perfecto y mostraron que había un cabo suelto. El fabricante del pelele con el que lograron cobrar la suma asegurada de Madiedo se percató del fraude y, desde entonces, chantajeaba a los integrantes de la banda de estafadores para beneficiarse del botín. Cuando Balmori desapareció, y con ello su contacto inmediato, decidió comunicar a La Mutua que habían sido estafados. El director de esta compañía denunció formalmente ante instancias judiciales.

\footnotetext{
7 Recurso de apelación de Francisco Cerezo contra el juez $2^{\circ}$ de Instrucción que le negó la libertad bajo caución en el proceso que le instruye por estafa, 24 de julio de 1905, AGN, TSJDF, c. 380, exp. 67479.

8 “El jurado de los Peleles”, El Imparcial (22 sep. 1906).
} 
En suma, durante los últimos meses del año 1900 y los primeros de 1901 se llevaron a cabo varias operaciones de seguros, cinco por el agente Eduardo Balmori Calguera, y todas ellas fueron denunciadas como fraudes. Los implicados fueron asegurados y pocos meses después se notificó de su muerte. Había cuando menos dos técnicas para engañar a las compañías. En la primera se presentaba en éstas una persona que no correspondía con la identidad del asegurado. Es decir, se trataba de un cambio o suplantación de identidad. La segunda consistía en simular la muerte, certificar médicamente al presunto difunto y practicar el entierro de un maniquí o bien del cuerpo de otra persona. Después de ese ciclo, se redimía la póliza para cobrar el seguro de vida. ${ }^{9}$

Por estos motivos fueron arrestados 18 sujetos como presuntos responsables de fraude y tentativa de estafa. Tres fueron considerados como principales. De Ciudad Porfirio Díaz (la actual Piedras Negras) fue remitido Francisco Cerezo por el jefe político, mientras que en la capital encontraron a Emeterio Celorio y Francisco Santoveña, que respectivamente habían contratado pólizas en las sucursales de Puebla y Tlaxcala para después cobrarlas en la ciudad de México. ${ }^{10}$ Con ello se completó el cuadro de estafas y muy pronto se percibió una especie de banda de la cual estaban prófugos los supuestos directores. La profesionalización de los delincuentes, sus relaciones criminales, savoir faire o técnicas para robar, falsificar, estafar y defraudar animaron la esfera pública. ${ }^{11}$

9 Diligencias instruidas en el Juzgado $2^{\circ}$ de lo criminal contra Emeterio Celorio por estafa. Apelación del auto de formal prisión, 2 de julio de 1902, AGN, TSJDF, c. 133, exp. 25147, 51 fs. La técnica de suplantación puede verse en el caso de Emeterio Celorio, quien animó a su hermano Fernando para contratar una póliza presentando ante el agente a otro individuo.

10 Recurso de apelación de Francisco Cerezo contra el juez $2^{\circ}$ de Instrucción que le negó la libertad bajo caución en el proceso que le instruye por estafa, 24 de julio de 1905, AGN, TSJDF, c. 380, exp. 67479, ff. 1-8.

11 Galeano, "Un artista". A diferencia de varios casos de falsificación reconstruidos por Diego Galeano, no consta que entre "los peleles" haya habido 
Las leyes, cifras o tendencias del fraude y la estafa, así como los perfiles sociales de quienes cometían estos delitos, refuerzan la hipótesis que relaciona el caso de los peleles a formas de trasgresión que tardaron en madurar en las concepciones jurídicas y criminológicas. Los tres puntos -marco jurídico, incidencia cuantitativa y rasgos sociodemográficos de los indiciados- son elementales para sopesar la novedad de las estafas contra las compañías de seguros en México.

En primer lugar, y por inéditos que fuesen, los actos cometidos por los "peleles" estaban tipificados como estafa que, a su vez, se concebía como una modalidad de fraude. De ese modo, constituían atentados contra la propiedad en la legislación penal vigente. En esencia, comprendían la obtención ilícita de alguna cosa o lucrar por medio del engaño y aprovechándose del error. Tomaba el nombre de estafa cuando el que quería hacerse de una cantidad de dinero en numerario, papel moneda o bien de un documento que importaba obligación, liberación o transmisión de derechos o cualquier cosa ajena mueble, conseguía que se le entregase por medio de "maquinaciones o artificios". ${ }^{12}$

Para entender cómo se percibían las estafas, conviene pormenorizar el conjunto de prácticas que el código penal consideraba similares. Así, algunas de éstas eran vender como si fuesen oro

algún artista, como el preclaro falsificador que, efectivamente, había estudiado en academias de pintura y perfeccionado la falsificación de papel moneda en el circuito platense (Buenos Aires, Montevideo y Pelotas).

${ }^{12}$ Código penal para el Distrito y territorios federales (1871), arts. $413^{\circ}-432^{\circ}$ : Dublán y Lozano, Legislación, t. XI, pp. 645-647. Es importante destacar el carácter inédito de estas estafas y que no se repitieron. Algunas noticias de suplantación de cadáveres fueron posteriores. Para periodos subsiguientes en Estados Unidos, se decía que los atentados y crímenes ejecutados exitosamente eran mucho más abundantes que los descubiertos y castigados. Varios pasaban por simples accidentes, y los más comunes eran relativos al cobro de pólizas contra incendios. Véase MANEs, "Insurance”, p. 39. 
y plata metales que no lo eran, ganar un juego de azar mediante el engaño, obtener dinero o un servicio por medio de libranzas, letras de cambio o cheques a sabiendas de que no tenían fondos, entregar en depósito algún saco, bolsa o arca cerrada haciendo creer al depositario que contenía dinero, alhajas o algún objeto valioso, así como vender a dos personas una misma cosa. Como se advierte, los fraudes suponían algún grado de abuso de confianza en una época en que el honor se consideraba una cualidad personal definitoria.

Por ello, llama la atención que esto fuera desestimado al definir la pena, pues el estafador sufría el mismo castigo que, atendidas las circunstancias, se le imponía al que había cometido robo sin violencia $\left(\operatorname{art} .415^{\circ}\right)$, cuya penalidad variaba según el valor del hurto (art. $376^{\circ}$ ): si era menor a 5 pesos, debía pagarse una multa del triple o arresto; mayor a 5, debía sufrir arresto mayor; si lo robado se evaluaba entre 100 y 500 pesos, estaba prescrito un año de prisión, que se elevaba a dos cuando el valor oscilaba entre 501 y1000. Por último, cuando el valor superaba los 1000 pesos se aumentaba un mes de prisión por cada 100 de exceso, sin poder rebasar la pena de cuatro años, lo que equivalía a una tercera parte de la sanción estipulada para homicidio intencional simple (art. $\left.552^{\circ}\right)$.

Ahora bien, la pena a los estafadores podía reducirse a la mitad cuando se restituía lo robado y se pagaban los daños antes de ser pronunciada la sentencia contra el delincuente. A la pena se sumaba la suspensión en el ejercicio de su profesión si el abuso de confianza lo cometía un abogado, escribano, actuario o notario, procurador, agente de negocios o corredor $\left(410^{\circ}-\mathrm{I}\right)$. Independientemente de estimarse bajas para fraudes tan cuantiosos, está claro que ni por asomo se consideraba una estructura u organización, como sí lo había en cambio para robo con violencia (por ejemplo, pudiera pensarse en bandolerismo), pues el asalto cometido por "cuadrillas de ladrones" se castigaba con 12 años de prisión (art. $402^{\circ}$ ). 
Además de que la penalidad era igual que para robo simple, hasta entonces poco se había revisado o cuestionado el marco jurídico en torno al fraude y la estafa. Y es que las cifras muestran el verdadero carácter limitado de esta figura delictiva, que además tenía expresiones tan diversas como el pequeño fraude por libranzas falsas en pequeña cantidad, pagarés, la venta de acciones y bonos de empresas inexistentes y una variada gama de prácticas de abuso de confianza. Acaso estaban como antecedentes medianamente impactantes en la esfera pública los casos del suplantador de identidades Malagamba o, de manera más reciente, Karsenty Casés (un defraudador que redimió bonos y acciones de una empresa falsa), pero las más comunes se relacionaban con engaños en billetes de lotería, el cuento del tío y el fraude del testamento. ${ }^{13}$

El segundo asunto se refiere a las tendencias cuantitativas de la estafa y el fraude. Según el informe del procurador de Justicia del Distrito Federal, en 1900 detuvieron a 122 individuos por estafa. Solamente fueron consignados 34 y tan sólo 2 enfrentaron proceso. Supongamos entonces que un número indeterminado de estafas se diligenciaron bajo el delito de fraude. Incluso así, de 91 detenidos solamente hubo 18 consignaciones en las comisarías, pero éstas ni siquiera resultaron en procesos penales.

El fraude y la estafa, por lo tanto, no existían en la criminalidad real. Es altamente probable que pocos se judicializaran por motivos diversos, como el estatus social de quienes los cometían, la falta de pruebas o bien porque las instituciones de justicia se ocuparon de otros delitos, como robo y lesiones. La mayoría de los sospechosos pertenecían a sectores populares y marginales.

13 Boletín de Policía (19 sep. 1909). Por ejemplo, un individuo le vendió a otro en 15 pesos un billete de Lotería Nacional diciéndole que había sido premiado con 500 pesos y le mostró una lista falsa. Sobre las estafas que se llevaban a cabo con base en "guiones", véase Piccato, "De otarios", pp. 266-276. 


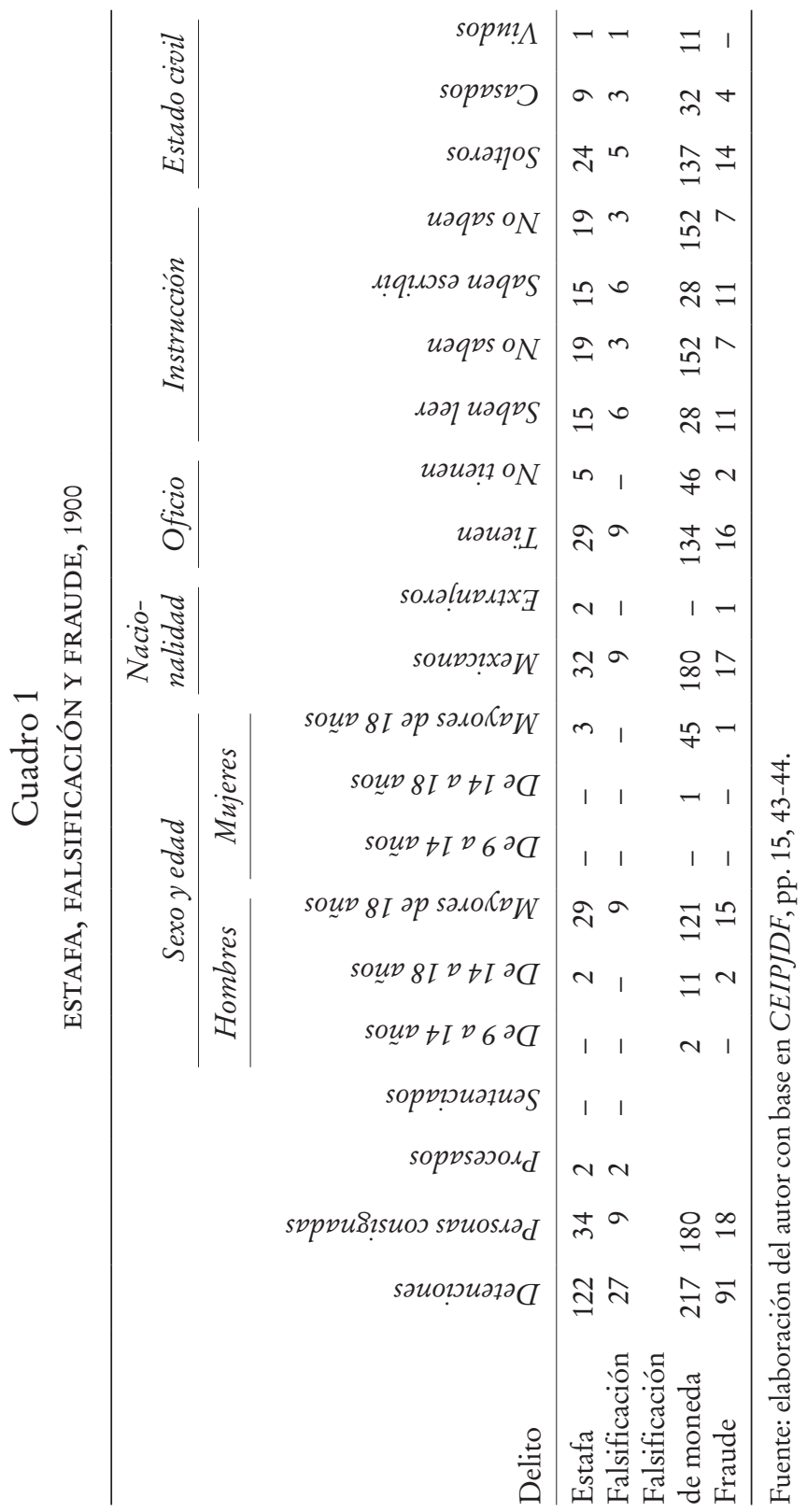


Por este motivo, los criminólogos conceptualizaron al sujeto criminal contorneado por determinismos físicos y raciales. ${ }^{14}$

Si bien la información no permite trazar un perfil social acabado, sabemos que en las consignaciones por fraude y estafa figuraron 48 hombres y solamente 3 mujeres. Salvo 4 individuos, todos tenían la mayoría de edad, mientras que 3 eran extranjeros. Cabe señalar que en su mayoría eran cualificados, pues 16 tenían oficio o profesión, mientras que 26 sabían leer y escribir. En contraste con los rasgos mencionados, los "peleles" tenían una composición social atípica frente a los datos citados -ni qué decir frente a las características sociodemográficas del grueso de los consignados por otros delitos-. Con los datos disponibles, resulta que en su mayoría eran varones y promediaban 37 años, lo cual no entraña ninguna novedad. Resulta interesante, en todo caso, que la mitad eran extranjeros de los cuales, salvo un peruano, predominaban españoles. Otra diferencia significativa es que todos leían y escribían, algunos eran propietarios y todos se desempeñaban en oficios que rendían de ingresos medios a altos: comerciantes, agentes o empleados.

A propósito de la población foránea y de la preponderancia del comercio de abarrotes, debe decirse que México no fue un receptor masivo del gran aluvión migratorio que cruzó el Atlántico entre 1880 y 1935. De hecho, el censo de 1900 solamente contabilizó 57507 extranjeros: 16000 eran españoles y 15000 , estadounidenses. En números absolutos y a diferencia de otros polos de inmigración europea en América Latina, llegaba a territorio mexicano una "insignificancia". ${ }^{15}$

Con todo, su importancia cualitativa resultó notoria, pues precisamente como la mano de obra no calificada bastaba,

14 Buffington, Criminal, pp. 38-63; Piccato, City, pp. 50-72, y Speckman, Crimen, pp. 71-114.

15 SÁnchez-Albornoz, La población, p. 175. 
recibió inmigrantes que gozaban de una posición privilegiada. ${ }^{16}$ Dentro de ésta, el giro de abarrotes y almacenes fue colmado por gallegos, asturianos y santanderinos. Confirmaban esta tendencia Balmori, Celorio, Santoveña y Madiedo, puesto que los principales responsables en el asunto de los "peleles" eran originarios de Asturias. Se habían conocido en México cuando menos dos generaciones y encontraron en los Balmori un paisano y benefactor que los acomodó en empleos de diversa índole. La importancia del paisanaje y la solidaridad tuvo diversas muestras en el asunto de los peleles.

Emeterio Celorio Platas era originario de España, casado y dueño de una tienda donde empleó a su hermano. Por mucho que lo apoyó, tuvo que internarlo en el Hospital Español debido a su alcoholismo, donde finalmente murió de tuberculosis. Un gendarme atestiguó que conocía a Fernando Celorio desde hacía cuatro años, que éste se embriagaba con frecuencia, tenía mal semblante y las piernas hinchadas. Durante ese tiempo, fue conducido a la $2^{\mathrm{a}}$ Comisaría por causar escándalos en numerosas ocasiones y el gendarme confirmó que Fernando pedía dinero para emborracharse. A esta versión se sumó el testimonio de un amigo del difunto, quien confirmó que en sus últimos días se encontraba mal de salud, era borracho y pobre, pero su hermano Emeterio le ayudaba con sus gastos.

Además de los españoles hasta aquí mencionados, compartían una condición social media los mexicanos que participaron de las estafas. Francisco Cerezo era propietario de un comercio situado en un populoso barrio de la capital y fue aprehendido en Coahuila, donde fraguaba otra estafa contra una compañía de seguros en connivencia con Rodríguez Zamora y Claudio Ortiz, con quienes supuestamente formaría una sociedad agrícola. Primaban entre ellos, cuando no lazos de parentesco o paisanaje,

${ }^{16}$ Lida, Inmigración, pp. 84-85. Este flujo para nada excluyó de su contingente a infractores y transgresores de la ley penal (pp. 42-43). 
sí de profunda amistad. Eran hermanos Francisco y Vicente Cerezo, Ramón y Eduardo Balmori, Emeterio y Fernando Celorio, Bernardo y Vicente Santoveña, José y Manuel Madiedo. Participaron el compadre y el cuñado de Cerezo (Jesús Martínez y Jesús Campos, respectivamente). Los vínculos por compartir origen, como he dicho, fueron notorios. Los asturianos seguían el patrón migratorio que encadenaba parentesco con común origen regional e incluso local. Como si se tratase de una charada toponímica, Madiedo era oriundo de Villaviciosa, en la provincia de Oviedo. Las complicidades, entonces, se fundaron en esos vínculos. Amor Rubín, que llevaba 25 años en México y era dueño de la tienda El Bucareño, aceptó ser testigo del testamento falso porque era paisano de los Celorio y los conocía desde que eran dependientes de las casas de don Benito Celorio, tío de ellos.

En cuanto a las competencias profesionales y oficios, predominaba el comercio. Solamente en casos excepcionales fueron relevantes en el papel que desempeñaron en las estafas. Por ejemplo, era bastante obvio que los médicos "inmiscuidos en las operaciones" se encargaban de emitir certificados de defunción. Algunos de éstos, como Federico Salazar, alegaban que habían sido engañados: que en efecto habían cuidado la enfermedad de pacientes como Jesús Yarto, a quien había visto enfermo y cuando se enteró de su muerte no lo dudó ni un instante. Expidió el certificado de defunción sin examinar el cadáver porque no deseaba descuidar a sus pacientes en la calle Don Toribio 6. Entregó los documentos a Ramón Balmori, quien era su amigo y desconocía que se trataba de un delito.

Acaso dos tuvieron empleos estratégicos para cometer las estafas. Por un lado, Eduardo Balmori era agente de seguros y, por el otro, Juan Rodríguez Zamora era policía y no cualquiera: se desempeñaba como agente de las comisiones de seguridad que, como se sabe, actuaban de manera encubierta, tenían acceso a información e influencia sobre empleados 
públicos y pequeños burócratas. Cerezo aseguró que la idea de robar a las compañías de seguros le fue propuesta por el prófugo Rodríguez Zamora. Para ponderar lo atractivo económicamente de las estafas, recordemos que el salario de un agente de la Reservada era de 3 a 5 pesos diarios entre 1900 y 1904, por lo tanto, concretar un solo golpe de 10000 pesos a las aseguradoras equivalía a los ingresos que hubiera tenido en 9 o casi 15 años de servicio. ${ }^{17}$

Para una élite obsesionada con el honor, se trataba de sujetos que pudieran considerarse decentes y habían estado implicados personajes "honorables", como el abogado Arístides Fernández Pinto. ${ }^{18}$ Por su parte, Francisco Cerezo había heredado fincas y otros bienes que valían más de 10000 pesos. Esto es, se trataba de individuos con una posición socioeconómica bastante holgada. Todos estos motivos llevaron al fiscal a señalar que no estaban reunidos "para juzgar a uno de esos criminales de la clase más baja del pueblo, a quien les falta moralidad y cultura", sino a "reos de ilustración nada común y que conciben, maduran y premeditan sus planes" para concretarlos de manera encubierta o difícilmente comprobable. El calificativo de cuello blanco para estas formas de delincuencia todavía no se había formulado. ${ }^{19}$ Sin embargo, los estudios sobre las prácticas y actitudes del robo muestran que los protagonistas de las grandes estafas no eran sujetos populares ni marginales. ${ }^{20}$

\footnotetext{
17 LIPEEF, pp. 34-41.

18 "Cabos sueltos", El Popular (22 jun. 1902).

19 Habría que esperar los estudios de Edwin Sutherland sobre los delincuentes de cuello blanco.

20 Palma, Ladrones, p. 257. Como señala Daniel Palma para el caso de Chile: "Junto al bandolerismo o el hampa urbano brillaban con luces propias las grandes estafas y corruptelas, cuyos protagonistas no eran precisamente ladrones de oficio, 'rateros conocidos', vagos o gañanes, sino 'caballeros de tarro y levita”, p. 257.
} 
LAS VÍCTIMAS: COMPAÑÍAS DE SEGUROS DE VIDA

Las características de las estafas -participación de alrededor de veinte personas, maquinación de varias etapas o fases para engañar a las compañías y empleo de técnicas de falsificaciónsugieren una obviedad: tuvieron una estrecha dependencia con el capitalismo financiero. Sin las compañías de seguros hubiera sido imposible siquiera pensar en los fraudes atribuidos a los peleles. Dos de las compañías defraudadas eran sucursales de la New York Insurance Company y de The Equitable, con sus respectivas matrices en Nueva York. Ambas fueron las primeras en establecerse en territorio mexicano y "que de forma pionera y con mucha lentitud introducen el negocio y las prácticas estadounidenses del seguro de vida". ${ }^{21}$ Según Douglas North, dichas compañías pasaron de tener 150 a 5000 millones de dólares en seguros entre 1865 y 1905. Además de perfeccionar cálculos actuariales, minimizar la especulación o, cuando menos, sistematizarla por medio de la probabilidad, las aseguradoras implementaron diversos tipos de pólizas, como el método de tontinas. ${ }^{22}$

La consolidación de estas empresas en el mercado estadounidense no fue necesariamente igual en territorio mexicano, donde se decretó la ley del seguro hasta el 16 de diciembre de 1892. En materia de seguros de vida operaban, entre otras, La Equitativa, La Mexicana, La Fraternal, La Mutua, la New York Life, La Germania de N. Y. y la Mutual Reserve Fund. Sería objeto de un estudio en sí mismo historiar cada una de estas compañías,

${ }^{21}$ Riguzzi y Ríos, Las relaciones, vol. 2, p. 55.

22 North, "Capital”, p. 239. La historia sitúa el origen de las tontinas en el banquero italiano Lorenzo de Tonti en el siglo xvir (p. 241). El esquema tuvo variantes posteriormente, pero en esencia los inversores creaban un fondo aportando el capital inicial y recibían intereses el resto de su vida. Cuando uno de los participantes moría, el interés que recibía el resto se incrementaba. Si morían todos, el capital restante regresaba a las arcas públicas o bien a la empresa. 
y tal vez el caso de La Equitativa resulte de singular interés. Su éxito en el mercado urbano obedeció a que ofrecía garantías institucionales a la incertidumbre de la clase media comercial, en especial ante la falta del jefe de familia. ${ }^{23}$

En 1865 se estableció en México la Equitable Life Insurance Co. El interés creció cuando el presidente de la compañía recibió en Nueva York al general Estanislao Canedo, que entonces era administrador de la agencia en México y que incluyó a Porfirio Díaz en el buró local. Bajo la responsabilidad de Dionisio Montes de Oca, la filial mexicana de esta agencia creció, compró un edificio y enfrentaría problemas con la ley de seguros de 1892, al elevarse el impuesto y exigir un depósito. Montes de Oca renunció por endeudarse con la sociedad, que reanudaría sus negocios tan pronto consolidó su sede en el edificio de la esquina entre Vergara y Cinco de Mayo. ${ }^{24}$ Por lo tanto, al momento de ser víctima de la estafa tenían poco de haberse reestablecido y reanudado en plenitud sus negocios, hasta que en mayo de 1911 la Revolución ocasionó de nuevo su salida del territorio mexicano. ${ }^{25}$

Mientras operó, había una importante penetración de las compañías de seguros para casas comerciales protegidas contra incendios y robos, donde los fraudes también fueron recurrentes. De las que aseguraban la vida se decía que respondían a "una necesidad social” y arribaron desde Estados Unidos, donde se

23 Zelizer, "Human Values", 593.

${ }^{24}$ CEHM-CARSO, Carta de Luis G. Méndez a José Y. Limantour, 12 abr. 1899, fondo CDLIV (Colección José Y. Limantour), $1^{\text {a }}$ serie, carp. 33, doc. 8873 , f. 1 .

${ }^{25}$ Luego, en 1922 La Equitativa volvió a entrar a territorio mexicano, igual que argentino, cubano, brasileño, chileno, etc. Buley, The Equitable, pp. 51, 80 y 184. Más allá de obras realizadas por las propias compañías, son relativamente escasos los estudios sobre las aseguradoras en México. Henry B. Hyde. Sobre la expansión de los seguros de vida, véase VAN LeEuwen, Mutual, pp. 156-159 y 268. Por ejemplo, en los Países Bajos había 3 en 1860, pero tres décadas más tarde sumaban 23. 
explotó ese giro con "grandes utilidades". Tan sólo durante el decenio de 1883 a 1893, las tres compañías principales cotizaron 1759738176.60 pesos de oro. Había además dos empresas mexicanas importantes, como La Fraternal, que permitía asegurar a cualquier persona con base en varios esquemas de pólizas según la edad, estado y profesión (plan de vida o limitado, capitalizados, dotales de niños, accidentes, etc.). Por su parte, La Mexicana tenía mayor capital y se le reconocía por abrir el camino entre las "gigantescas" La Equitativa y Nueva York, "las cuales con su perfeccionado sistema de reclamo y sus balances con cifras que causa[ba]n vértigo, levantaron en pocos años abundante cosecha, muy beneficiosa para ellas y de pequeños resultados para el país". ${ }^{26}$

Con la aparición de las compañías nacionales, disminuyeron las ganancias de las estadounidenses en tal proporción que " $\mathrm{La}$ Equitativa vióse obligada a poner en liquidación su sucursal, pretextando carecer de apoyo en los poderes públicos y que se la agobiaba con impuestos". En realidad "se vio abandonada por el público” según otras versiones, mientras que La Mutua se sostenía

como el tuberculoso cuyos pasos oscilan entre la vida y la muerte [...] Hablillas y murmuraciones aparte, en la conciencia de todos está que la razón no está sino que, como dejamos dicho [...] de que la decadencia de las compañías extranjeras no procede de otra causa más que del hecho innegable de que las corrientes del público se apartaron de ellas para dirigirse a las nacionales. ${ }^{27}$

Tal incremento del seguro de vida obedecía, posiblemente, a que para contratar una póliza había pocos controles adicionales

${ }^{26}$ Figueroa Doménech, Guía, t. 1, pp. 219-223. Presidía La Fraterna Ignacio Pombo y la dirigía Enrique Aragón.

27 Figueroa Doménech, Guía, t. 1, p. 223. 
a lo prescrito en el código de comercio de 1889. Además, debe considerarse que no existían identificaciones y, si acaso, el acta de nacimiento era el único documento oficial que se requería. Así, el interesado acudía con testigos, hacía su solicitud por escrito y se le hacía un reconocimiento médico. Una vez autorizado por el agente de seguros, pagaba generalmente cada mes los "premios". La suma de éstos estaba garantizada para los beneficiarios, pero también el valor indicado en la póliza. ${ }^{28}$ Subsistían, de alguna manera, la confianza en los acuerdos comerciales y cierta precariedad en el registro civil.

Independientemente de estas apreciaciones, en vísperas de que los peleles fueran descubiertos, La Mutua-que reestableció su sucursal en el número 4 de la $2^{\mathrm{a}}$ calle de Independencia- publicitaba tener 4000 pesos en bonos del gobierno federal y su gerente general, John Hatfield, aseguraba que se habían pagado más de 1000 millones de pesos a los tenedores de pólizas. ${ }^{29} \mathrm{Se}$ desconoce el asunto que trataron en una charla personal el agente general de La Equitativa y Limantour en enero de 1900 "por unos cuantos minutos" ${ }^{30}$ Entonces todavía pasaban inadvertidos los cobros fraudulentos de pólizas realizados por Balmori, los Madiedo y compañía. En marzo de 1902 los gerentes generales W. P. Massie y W. S. Le Mon se entrevistaron nuevamente con

${ }^{28}$ Además de los fondos judiciales, algunos archivos personales conservan pólizas de seguros. Por ejemplo: CEHM-CARSO. Póliza de seguros impresa, México, 1o de septiembre de 1892, Archivo José Luis Blasio, fondo Ernesto Cuevas, serie Manuscritos de José Luis Blasio, carp. 4, doc. 386, $\mathrm{f} 1$. Regulaban los contratos los arts. $392^{\circ}-448^{\circ}$ del código de comercio, en Dublán y LozANo, Legislación, t. XX, pp. 590-595. Por último, véase "Seguros sobre la vida", El Abogado Cristiano Ilustrado (1o mayo 1886).

29 "La Mutua", Jueves de El Mundo (23 ene. 1902). Anunciaban esto al calce de grabados que representaban accidentes. Muchos de éstos se atribuían a los tranvías eléctricos.

30 CEHM-CARSO, Carta de Refugio Bilderrain a José Y. Limantour, 19 ene. 1900, fondo CDLIV (Colección José Y. Limantour), $2^{\mathrm{a}}$ serie, carp. 10, doc. 17945, f. 1. 
el secretario de Hacienda, pero tampoco hay indicios suficientes para pensar que siguieron sus recomendaciones para denunciar penalmente a los sospechosos por estafar a la empresa de la que eran gerentes generales. ${ }^{31}$

Al margen de estos intercambios, la capital mexicana de la década de 1900 tenía alrededor de 350000 habitantes. Al crecimiento demográfico se sumó una modernización con efectos en las prácticas delincuenciales. ${ }^{32}$ Esta evolución del delito en materia de fraude, estafa y falsificación se ligó, de manera inextricable, con el capitalismo financiero. ${ }^{33}$ Cuando los peleles cometieron sus engaños, la falsificación se había extendido de circulante metálico a documentos de cambio: desde papel moneda y cheques hasta bonos y acciones. Sería aventurado tildar de nuevas estas formas de delincuencia, pero adquirieron mayor consistencia, técnica y organización. Los fraudes contra las aseguradoras habían crecido en el reclamo de bienes, pero eran raras en seguros de vida. Lo era aún más la falsificación de cadáveres, mientras que el lucro con cuerpos era inédito salvo en otras latitudes, donde además había implicado violencia, como el caso de los llamados "resurreccionistas", que en 1827 mataron a "locatarios para vender sus cuerpos a la disección" ${ }^{34}$ La propia novela Frankenstein de Mary Shelley abundaba en referencias a ese tráfico entre ilegal y macabro de cuerpos humanos para la ciencia. De manera semejante, los fraudes en contra de compañías de seguros se habían llevado a efecto con cadáveres reales, pero no con muñecos.

Ahora bien, el juicio y su consiguiente resultado de cuatro personas sentenciadas pudiera considerarse como una victoria

31 CEHM-CARSO, Carta de W. P. Massie a José Y. Limantour, 31 mar. 1902, fondo CDLIV (Colección José Y. Limantour), $2^{a}$ serie, carp. 15, doc. 213, f. 1. 32 Piccato, “De otarios", p. 257.

33 Para el proceso contra Samuel Karsenty, véase DJ (9 mayo 1905), así como PaYno, Amparo.

34 Kalifa, Los bajos fondos, p. 27. 
de los implicados. Es verdad que el gran ganador fue Balmori, quien ni siquiera fue llamado a comparecer. Las compañías lograron exhibir los fraudes ante la opinión pública y buena parte de las estafas no se concretaron ni entrañaron pérdidas, pues simplemente no pagaron las pólizas reclamadas al constatar que se trataba de fraudes. Aun así, el juicio mermó la credibilidad de The Equitable y de la New York, cuyas matrices fueron investigadas por escándalos de corrupción. Esto pudo influir en la percepción de los miembros del jurado.

\section{JUICIO Y CASTIGO DE LOS PELELES}

Del 14 al 26 de septiembre de 1906 se llevó a cabo el juicio para resolver el "asunto de los peleles" ${ }^{35}$ Salvo Cerezo, todos habían conseguido libertad provisional tras pagar las respectivas fianzas. ${ }^{36}$ Así, de las primeras diligencias resultaron encausados 18 individuos. Uno de ellos falleció y 2 obtuvieron libertad bajo fianza antes del juicio por jurado popular. Del subsecuente proceso solamente fueron condenados 4 individuos y 11 resultaron absueltos. Entre los primeros, la sanción más severa fue en contra de Francisco Cerezo, quien fue condenado a cuatro años de prisión (computados desde 1904) y a pagar una multa de 1600 pesos. Por complicidad, Fernando Piña y Ponce de León fue sentenciado a dos años y a pagar 650 pesos, lo mismo que Jesús Campos Méndez, mientras que la sentencia en contra de José Santoveña fue de un año y 11 meses de prisión. Si bien se demostró la responsabilidad de su hermano, éste fue absuelto toda vez

35 AGN, TSJDF, c. 183, exp. 32839. Apelación de sentencia por estafa e incidente no especificado. Segunda sala (penal), ff. 7-13. Asimismo, AGN, TSJDF, c. 137, exp. 27095, José Madiedo Viñas en apelación de sentencia por estafa frustrada, 27 de agosto de 1902, ff. 21-39.

36 AGN, TSJDF, c. 318, exp. 55519, Libertad preparatoria por el delito de estafa, 6 de octubre de 1904, ff. 2-19. 
que habían pasado tres años entre el delito y la averiguación, y siete cuando comenzó el juicio. ${ }^{37}$ El resto recuperó su libertad. ${ }^{38}$

Más allá del resultado de las sentencias, importa subrayar que durante el juicio se homologó la versión de los indiciados. De manera unánime, señalaron que los autores intelectuales y principales responsables estaban prófugos. Los encargados de la defensa argumentaron que sus clientes habían sido manipulados por el exagente de seguros Eduardo Balmori y el policía reservado Juan Rodríguez Zamora. Con ello, los abogados Ramón Prida y Manuel Ramos Pedrueza parecieron influir sobre la percepción en torno a los "peleles" que ocupaban el banquillo de los acusados. En sentido estricto, la culpabilidad se acreditaba cuando había posesión de "la cosa robada”. Esto explica la razón por la que fueron absueltos casi todos los involucrados, pues se les sorprendió antes de que se les pagase el dinero de la póliza. La tentativa, por lo tanto, no acarreaba pena alguna y fueron exonerados por falsedad, pues no se comprobó que estuvieran coludidos, alegando que tanto los médicos como el notario también habían sido engañados. De manera adicional, casi ninguno tenía antecedentes penales ni fueron denunciados por violar leyes de exhumación, lo cual fortalecía la versión de que siguieron instrucciones de los Balmori.

Es importante subrayar que el juicio inclinó la balanza en la opinión pública. Si en 1902 los presuntos implicados fueron desaprobados, cuatro años después la indignación se concentró en Eduardo Balmori y, de manera inusitada, se juzgó negativamente a las compañías de seguros. A pesar de que el fiscal insistió

37 AGN, TSJDF, c. 465, exp. 84043. Compañía de Seguros sobre la vida La Mutua S. A. contra Bernardo Santoveña, 24 de julio de 1906, 81 fs.

38 "Fin del famoso jurado de los Peleles", El Imparcial (25 sep. 1906). Francisco Cerezo obtuvo sentencias condenatorias por concebir, preparar y ejecutar el delito de estafa por medio de Claudio Ortiz a quien indujo por medio de "dádivas y promesas". En concreto, se hizo ilícitamente de una póliza de La Equitativa por valor de 16000 pesos. 
en que los delitos eran todavía más graves porque los acusados tenían una posición social respetable, hubo dos momentos diferenciables en el proceso contra los peleles. Al principio fueron vilipendiados enérgicamente como estafadores, mientras que en 1906 la antipatía se desplazó en contra de los prófugos y, en menor medida, contra las compañías de seguros. Debido a los alegatos de la defensa, dejó de hablarse tan despectivamente de los defraudadores, a quienes inicialmente se vilipendió por "sus trapacerías" y por pretender llevar una vida dispendiosa. En cambio, las aseguradoras fueron cuestionadas por diversos motivos. En primer lugar, se adujo su presunta incompetencia, pues se decía que "las compañías de seguros de vida ya no tienen vida, y tratándose de seguridad, no tienen ni un alfiler" ${ }^{39}$ En segundo lugar, porque el agente de una de las compañías había sido señalado como el autor intelectual y principal beneficiario de las estafas. El defensor Ramos Pedrueza expuso que la posición del "tribunal del pueblo" estaba entre las "poderosas compañías de seguros" y "los pobres desheredados sentados en los banquillos". Considerados como títeres, los periódicos explotaron la polisemia del término pelele.

Otros subrayaron la relevancia legislativa y judicial que revestía este caso para la cultura jurídica. Entrevistados por la comisión revisora del código penal, el juez Martín Mayora -quien se encargó de las primeras averiguaciones- y el procurador general de Justicia, Luis López Massé, consideraron indispensable reformar el artículo $414^{\circ}$, porque era "irrisoria la pena que se aplicaba" a un delito grave, como "el conocido con el nombre de 'El asunto de los peleles"”, ya que "los delincuentes emplearon maquinaciones y artificios para hacerse indebidamente de dinero perteneciente a las compañías de seguros". ${ }^{40}$ Por tales

39 “\$100,000 por la cabeza del Lic. Miguel Gómez: ¡Jesús, cuánto pelele!”, El Popular (24 jun. 1902).

${ }^{40}$ Ismael Elizondo (juez correccional), "Estudios jurídicos. Proyectos de reformas al código penal”, DJ (1o oct. 1904). 
motivos, acumulaban delitos como falsedad y, por lo tanto, debía incrementarse una tercera parte a la pena (art. 208\%).

En contraste con la posición que tomaron los jueces y el procurador, la defensa de Prida equiparó la causa contra los peleles con un caleidoscopio en el que "hacían juegos a manera de pedazos de vidrios, fragmentos de la verdad despedazada”. Por su parte, el también abogado Ramos Pedrueza sostuvo que el juicio era una especie de "robo": "Aquí, señores jurados, todos han robado. Los acusados, a las Compañías; el Ministerio Público ha substraído de la culpabilidad a algunos de ellos; el Lic. Lomelí, me ha robado mi frase: la puñalada benigna". ${ }^{41} \mathrm{Se}$ advertía, entonces, una ridiculización que el fiscal tuvo que enfrentar para convencer, primero, la culpabilidad de los indiciados $y$, segundo, que estaban lejos de "sitiales dignos de delincuentes de baja ralea”. En atención a su posición social eran todavía más reprobables las transgresiones cometidas por individuos aparentemente "honorables" y que pertenecían a "familias honradas”. Nada entonces había de dudoso en los hechos ni en el juicio, pues señaló que se trataba de robos "por más que la moderna legislación” los definiera como estafas, mientras que calificó a los presuntos responsables de "aventureros sin honor" aclarando que no era "antiextranjerista”, sino que consideraba necesario subrayar la "negra fisonomía moral” de los principales responsables. En primer lugar, los hermanos Balmori se mantuvieron prófugos, sustraídos de la acción de la justicia y gozando del fruto de sus delitos en España y Francia. En segundo lugar, Arístides Fernández "murió triste y olvidado" en la cama de un hospital. Todos eran, según el fiscal, "personas ilustradas a las que consideró peligrosas para los intereses sociales”. En tercer lugar, Francisco Cerezo era "un individuo de cierta posición social", hijo de padres esforzados, con bienes y algo de fortuna, que había recibido "una buena educación”, pero en un momento

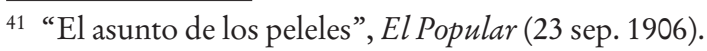


fue "ambicioso y malaconsejado" al elegir el "camino de la delincuencia". ${ }^{42}$

Los debates durante el proceso judicial produjeron impresiones igualmente negativas sobre las compañías de seguros, "cuyos manejos y ligeros procederes quedaron al descubierto" $y$ potenciaron la desconfianza pública al tiempo que, coincidentemente, circulaban noticias sobre dificultades para pagar las pólizas de tenedores legítimos. La "institución del seguro de vida, $\tan$ buena en principio, tan benéfica en todos sus resultados, está quedando en México como si jamás hubiera existido". ${ }^{43}$ Apenas en 1905 salió a la luz la "investigación Armstrong" con un informe que exhibió a las principales compañías de seguros, la corrupción en el manejo de las pólizas y los incumplimientos bajo el esquema de tontinas. ${ }^{44}$ En suma, el juicio tuvo un castigo formal para algunos de los defraudadores, pero la condena moral afectó por igual a víctimas y victimarios. Es posible que esto obedeciera a los "manejos y ligeros procederes" mencionados de soslayo por uno de los abogados defensores.

42 “El jurado de los peleles”, El País (23 sep. 1906).

43 "El jurado de los peleles y las compañías de seguros sobre la vida”, El Popular (3 oct. 1906). En 1905 hubo un litigio favorable a La Equitativa. El tenedor de la póliza reclamaba que había vencido el plazo de la tontina, pero el contrato era ambiguo al respecto: Esteban Parga contra La Equitativa, sociedad de seguros sobre la vida. Juicio ordinario mercantil sobre pago de una póliza, $D J$ (8 abr. 1905), pp. 665-672.

44 Ransom y Sutch, “Tontine Insurance”, p. 380. Las tontinas formuladas por Sheppard Homans se introdujeron en 1868 por la Equitable Life Assurance Society en Estados Unidos. Este nuevo tipo de póliza era distinto de los seguros estándar, en que las primas pagadas cubrían dos propósitos distintos. Una parte de la prima se destinaba al asegurado. La parte sobrante era depositada en un fondo de inversión manejado por la compañía de seguros. Este fondo crecía tanto por el ingreso de nuevos pagos como por las ganancias recibidas de la inversión. Después del periodo acordado (usualmente 20 años), la suma completa del fondo de la tontina era dividida entre los tenedores de pólizas sobrevivientes. 
IMAGINARIOS, DESESTABILIZACIÓN DE LA VERDAD E INCERTIDUMBRES

Con marcado humorismo, hubo representaciones inmediatas al finalizar el juicio. Por ejemplo, la publicidad de una marca de cigarrillos aseguraba que "los Peleles han quedado libres por haber fumado Glorias Nacionales", y no faltaron obras de género chico. ${ }^{45}$ Sin embargo, no todo fue tomado de manera superflua. El asunto de los peleles planteaba una organización del delito por el número de involucrados, la jerarquización y la división de atribuciones, así como por el grado de complejidad y sofisticación de los fraudes. De ello hubo varias expresiones en la esfera pública ocupada por periódicos de signo liberal o católico, lo mismo que por la gran prensa de las colonias de extranjeros así como la metropolitana y la satírica, donde se habló de la "genialidad de una banda de timadores", sobre Balmori "y socios", Cerezo "y su cofradía", sobre una "cuadrilla de estafadores de alta escuela", y otros epítetos que inscribían los fraudes contra las compañías de seguro en formas de criminalidad moderna. ${ }^{46}$

El asunto de los peleles dio ocasión para reflexionar sobre algunos pilares sociales. Unas décimas lamentaban que había "gentes que parecen gentes", pero que no eran otra cosa que "muñecos de cartón y paja". ${ }^{47}$ Las estafas también suscitaron preocupaciones sobre la relación entre cuerpo y verdad. Recordemos que se ha asociado al porfirismo con una mirada cientificista de la sociedad a un grado tal que, por mucho tiempo, se consideró que el positivismo fue la doctrina oficial de ese

\footnotetext{
45 “A propósito del jurado de los Peleles”, El Popular (26 sep. 1906). Había cartelones en las esquinas que anunciaban "Los Peleles, nombre regocijado que hace pensar en algo así como el cocoteo de payasetes funambulescos". "El género chico", La Patria (4 abr. 1903).

46 "A sensational fraud is exposed", Mexican Herald (5 mar. 1902), "Los Peleles y la estadística de la mortalidad”, El Mundo Ilustrado (15 jun. 1902).

47 Javier Santamaría, Jueves de El Mundo (10 abr. 1902).
} 
régimen. Más allá de dicha consideración, es notorio el auge del realismo naturalismo en expresiones artísticas y literarias. Pues bien, el caso de los peleles explotó la correspondencia entre el cuerpo y su representación para engañar a las compañías:

Cada ocho días tiene la Compañía de Seguros la indecible satisfacción de ir a presenciar la exhumación de un nuevo cliente, en forma de muñeco de palo, y la diligencia judicial que muchos creían tétrica y macabra, resulta graciosísima y motivo de risa interminable. Con la circunstancia agravante de que, con el tiempo, los peleles progresan y son más "artísticos", mejor acabados, verdaderas obras de arte. El último, por ejemplo, era un modelo en que el "escultor" derrochó las ricas galas de su fantasía. Al decir de la prensa [...] cualquiera lo habría tomado por una persona decente y no por guasón; tieso, grave, pálido, como corresponde a un muerto de buena familia; en el rostro escultural, perfectamente impreso el sello macabro de la muerte; las manos enguantadas, un pañuelo de seda al cuello: parecía un recaudador de casas en estado de merecer. Ya los circunstantes se inclinaban respetuosos ante tanta verdad, cuando las tripas de aserrín y los zapatos atornillados los hicieron desternillarse de risa... ¡ Oh!, qué chistosa fiesta, qué actitud tan hierática y qué pelele más gracioso. ${ }^{48}$

La falsificación de un cadáver podía motivar la risa, pero también generaba ansiedad. Se especuló sobre la cantidad de cuerpos falsos debajo de las lápidas. "Las reiteradas exhumaciones de peleles que han venido verificándose, y las más numerosas aún que amenazan realizarse a corto plazo, darán ocasión a un trabajo inmenso de rectificación estadística y llegarán a desvanecer, así lo esperamos, la calumnia que pesaba sobre nuestra salubridad

48 “Los peleles: burlas al público”, El Popular (18 jun. 1902). 
pública." ${ }^{49}$ Mediante el paroxismo, los comentarios se valieron de las falsificaciones para moralizar, pues la solemnidad de los cementerios y el respeto por su simbología habían sido objeto de "estafa y de burlas sangrientas".

Otra forma de defraudar a las compañías consistía en presentar el cadáver de una persona distinta al asegurado, tal como se verificó en tres de las estafas atribuidas a los peleles. ${ }^{50}$ Por mucho que las estafas estuviesen planificadas, no deja de sorprender cómo fueron engañados los testigos, incluidos facultativos que faltaron a su obligación. Cabe preguntar si acaso habían cambiado los ritos funerarios. Según Philippe Ariès, todavía a comienzos del siglo xx no se consumaba el ocultamiento de los difuntos y "la casa se llenaba de vecinos, de parientes, de amigos". ${ }^{51}$ Hay que decir que los peleles financiaron velorios de personas carentes de recursos y sin deudos, lo cual tal vez facilitó que suplantaran la identidad.

Cierto repudio hacia lo corporal propio de un pudor victoriano no fue ajeno a un médico contratado para ejecutar uno de los engaños. Sin embargo, el descuido fue más determinante. Originario de San Luis Potosí y médico homeópata de la Facultad de México, Félix Pérez también se formó como alópata sin llegar a examinarse ante el Consejo Superior de Salubridad y, por ende, carecía del título cuando se dedicó a curar "mediante los dos sistemas". Dijo conocer a José Madiedo en la casa donde padeció su enfermedad, situada en el callejón del Garrote, donde lo atendió a cambio de dos pesos del 21 al 23. Al día siguiente Manuel fue a su consultorio en la calle de la Misericordia para avisar que su hermano había muerto. Le pidió un certificado de

49 Dr. M. Flores, "Los peleles y la estadística de la mortalidad", El Mundo Ilustrado (15 jun. 1902).

${ }^{50}$ Está bastante documentado el uso de cadáveres de indigentes tanto para la disección como para cobrar seguros. En ocasiones, el peso y la altura del cuerpo develaron los engaños. MANEs, "Insurance", p. 39.

${ }^{51}$ ArIÈs, L'homme, pp. 553 y 569. 
defunción y "no tuvo inconveniente en dárselo". En descargo de su responsabilidad, señaló que pudo equivocarse en la curación,

[...] pero eso no sólo a mí, sino a todos los médicos de México y de todas partes del mundo les sucede muy a menudo. Certifiqué que había visto el cadáver, aunque no lo vi; pero eso también es una costumbre muy generalizada entre todos los médicos de esta capital, los cuales dan generalmente fe de haber visto a los cadáveres, sin que en realidad los hayan visto. ${ }^{52}$

Al confesar la desvinculación entre el médico y el trato directo con el paciente, mostraba no solamente una falta como profesional, sino que abrió la posibilidad para seguir el resto del engaño. Tras cobrar 20 pesos por el certificado, refirió que la farsa

[...] fue tan bien hecha que se efectuó velorio, se contrató carroza fúnebre, fue un vagón de dolientes, recibió con vela en mano, en el Panteón Francés, un cura al supuesto muerto, y lo condujo a la capilla a decirle responsos, no habiendo faltado quien derramara abundantes lágrimas al echar el último puñado de tierra sobre aquellos restos que en realidad no eran más que un muñeco. ${ }^{53}$

Aunque carecemos de fotografías de esos muñecos, hubo cuanto menos tres representaciones gráficas relevantes por aportar otras lecturas a los fraudes. El grabado "Los funerales del pelele" de Eugenio Olvera (1866-1934), publicado en Jueves de El Mundo, muestra la única representación de la que se tiene noticia de uno de los muñecos (véase la imagen 1). Destacado

52 "Sensacional jurado por estafa de 20,000 pesos", El Popular (21 ago. 1902). 53 "Sensacional jurado por estafa de 20,000 pesos", El Popular (21 ago. 1902). Los médicos debían certificar las defunciones por instrucciones del juez (art. $41^{\circ}-\mathrm{I}$ ): Reglamento de los juzgados del estado civil, 10 de julio de 1871, Dublán y Lozano, Legislación, t. XI, p. 527. 


\section{Imagen 1}

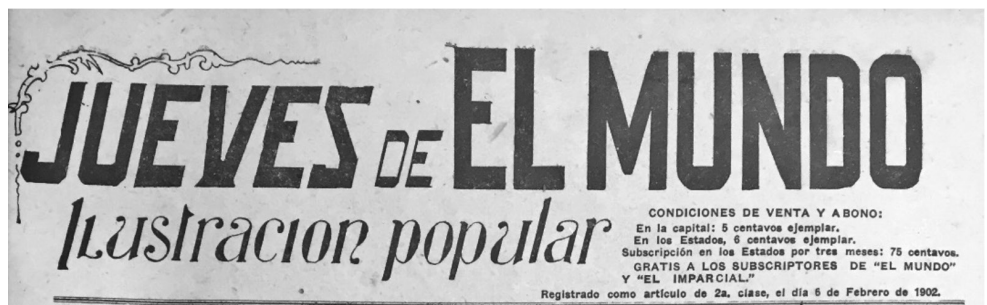

\begin{tabular}{lll}
\hline Marzo 13 de 1902.-Núm. 9. & Registrado como artloulo de 2a, ciase, el dia 6 de Febrero de 1902. \\
\hline \hline
\end{tabular}

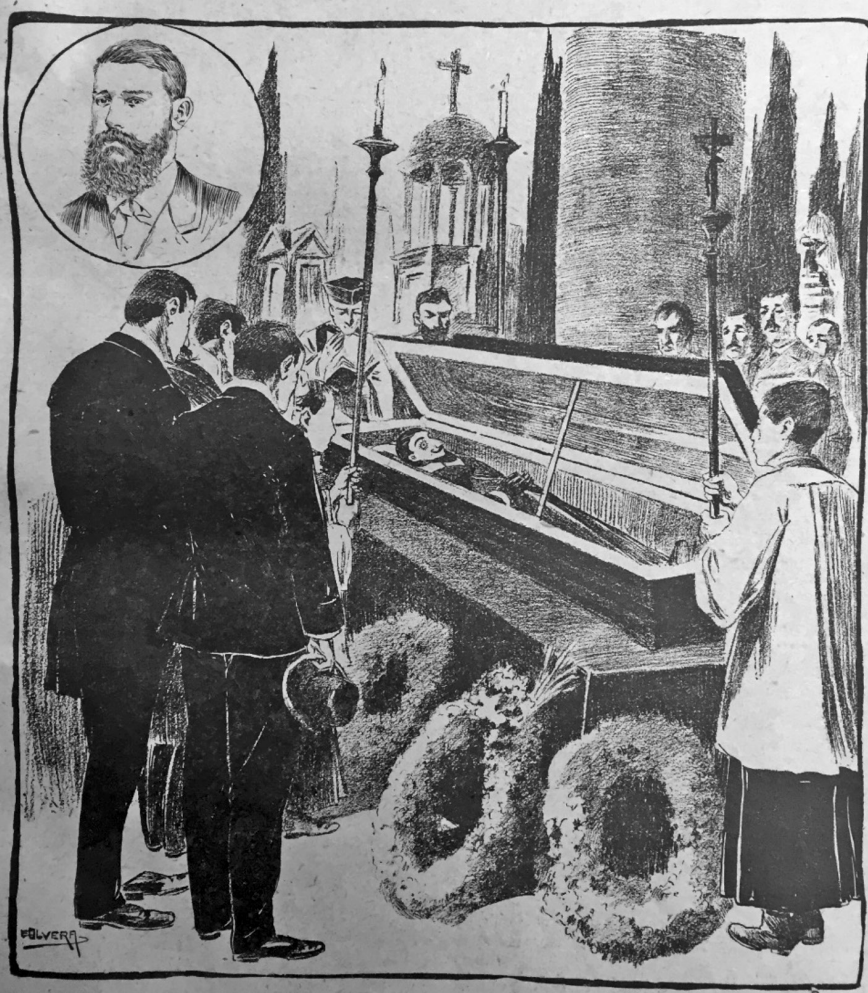

III tan bueno y cano como lo mueatra of retrato que flgura on osta plane.

Eugenio Olvera Medina, "Los funerales del Pelele", Jueves de El Mundo (13 mar. 1902). 
ilustrador en otros exponentes de la prensa satírica, Olvera recreó la farsa del entierro por medio de un retrato con marcado naturalismo y cuidado por el detalle de los personajes que compusieron la escena. El monigote del ataúd apareció trazado con rigidez, mientras que el resto actuaba según los cánones de un cortejo funerario. Si bien Jueves de El Mundo está lejos de considerarse un órgano crítico, el episodio de los Peleles provocaba risa y ridiculizaba a las compañías de seguros. La generalizada tomadura de pelo y el grado de sofisticación muestran lo que el testimonio del médico había señalado. Según éste, se había limitado a emitir un certificado sin auscultar previamente el cadáver, pero los Madiedo y compañía habían montado toda la escena que dio verosimilitud a la muerte de José. Había, entonces, alusiones a la organización de los estafadores como profesionales de la simulación.

En ese sentido, un montaje o collage dio una expresión gráfica a la noción de banda u organización. Figuraban en esta composición los retratos de identidad de 12 de los involucrados, así como la imagen del pelele que representaba a José Madiedo. Ofrecía así una representación basada en testimonios de los indiciados que mostraba los liderazgos y jerarquías. En segundo plano figuraban objetos alusivos a las estafas y a los procedimientos que llevaron a cabo los procesados. Recreó los entierros (o tal vez las exhumaciones) e integró elementos sobre el caso criminal: una celda, un mausoleo y, desde luego, una póliza de La Mutua (véase la imagen 2).

Algo semejante ofreció una viñeta compuesta por numerosos símbolos (imagen 3). Allí aparecen los estafadores elegantemente vestidos con chaquetas, levitas, corbatas y uno de ellos porta una chistera. Otros elementos en la cornisa superior izquierda reprodujeron algunas pólizas y costales rebosantes de monedas, igual que en la derecha, donde se añadían algunas cartas de baraja española, probablemente aludiendo al juego y a la vida de tahúres. Protagonizan la escena dos personajes sujetando al 
Imagen 2

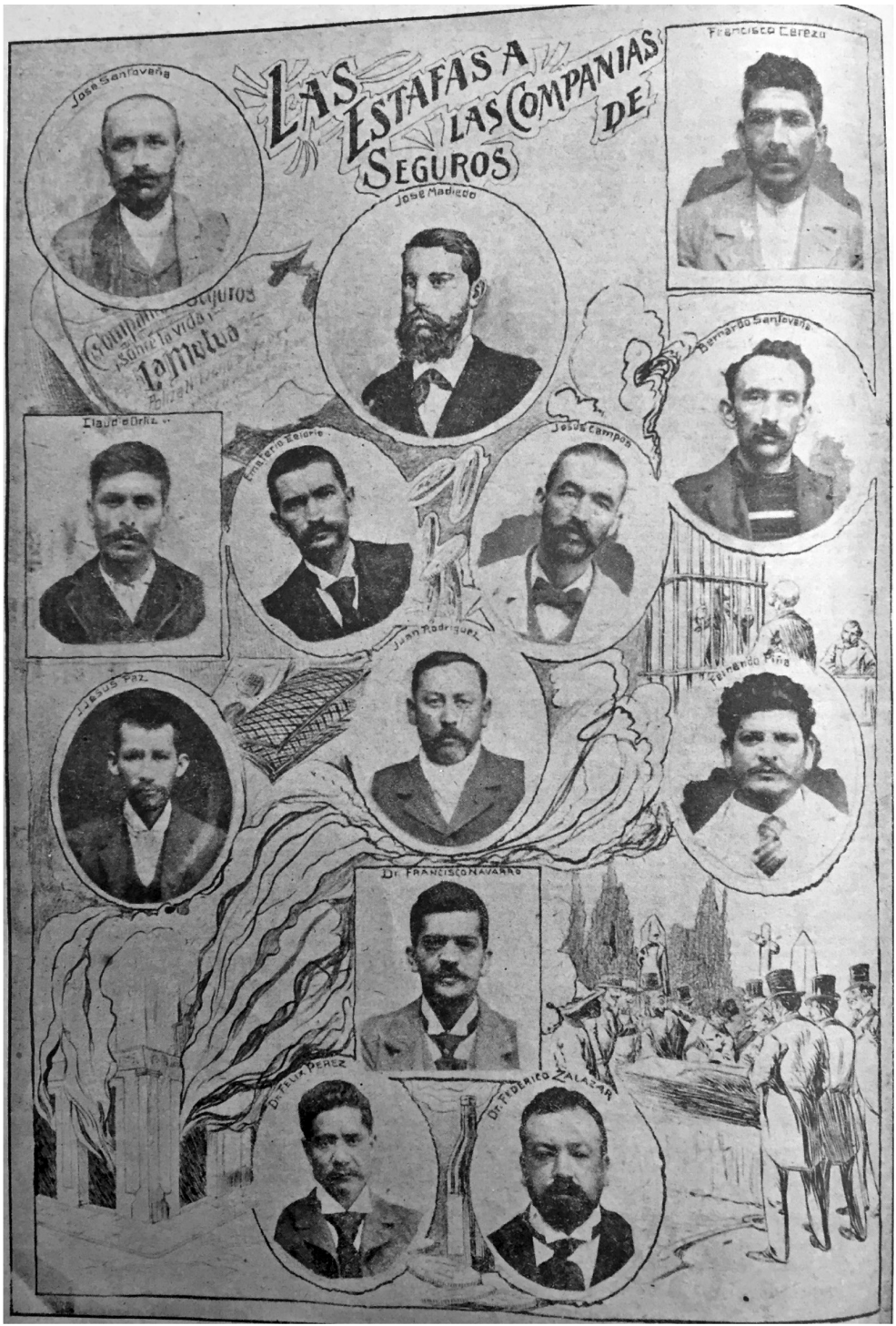

"Las estafas a las compañías de seguros", Jueves de El Mundo (3 jul. 1902). 


\section{Imagen 3}

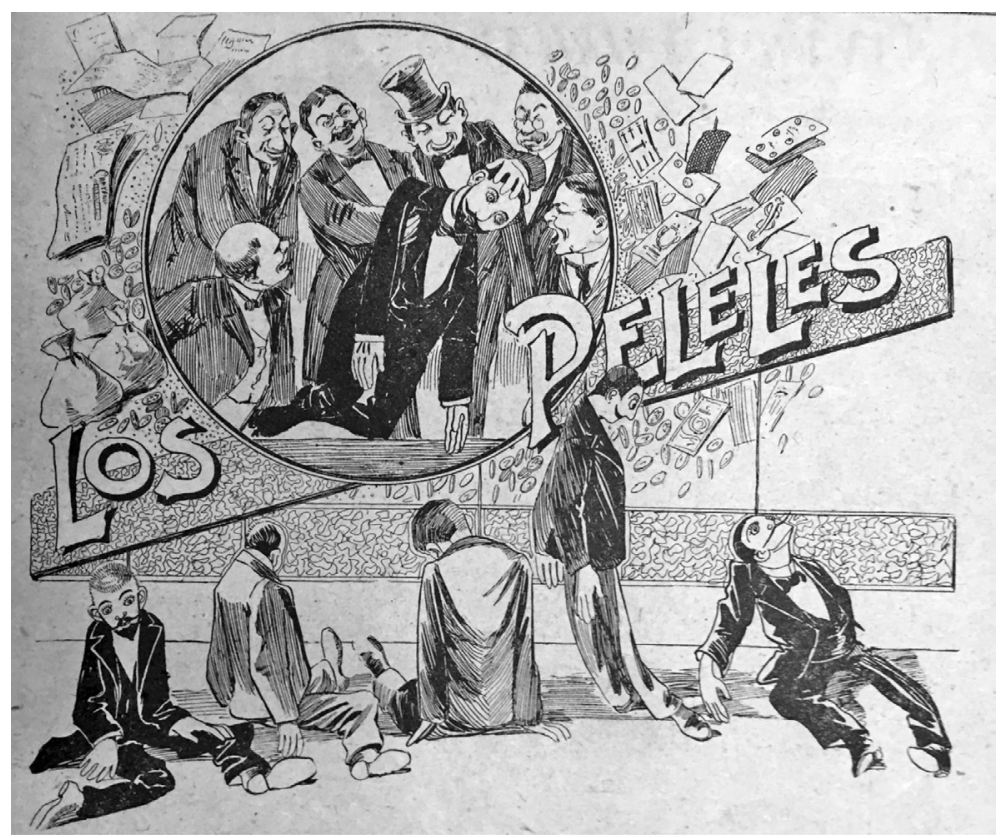

“Los peleles", Jueves de El Mundo (24 jul. 1902).

pelele, uno con clara mueca burlona y el otro aparentemente concentrado. En la parte inferior estaban retratados otros cinco muñecos, solamente uno pendiendo como marioneta y el resto en posturas afectadas, torcidos, desbalanceados y con las extremidades guangas. Expresaba de manera bastante gráfica otros registros que con humor y cierto cinismo increpaban: “¿qué otra cosa son los hombres más que peleles ni qué es la vida sino una farsa en que todo el mundo trata de proveerse de la mayor cantidad de muñecos posible, que se hacen andar con cuerdas, como graciosas marionetas, para representarlo todo, desde la honradez hasta el candor y desde la inocencia hasta el 
honor?" ${ }^{54}$ Consideraciones de esta índole sugieren que el caso de los Peleles fue empleado para desestabilizar certezas, criticar la simulación e insinuar la manipulación sin señalar nombres concretos. Finalmente, el caso sería reactualizado por medio del periodismo amarillista y releído en una clave distinta: los fraudes a las compañías de seguros aparecieron varias décadas más tarde como acto fundacional en la organización y profesionalización de la delincuencia, justo durante el contexto posrevolucionario, cuando las bandas de estafadores habían consolidado su presencia en las prácticas, pero también en el discurso criminológico y varias representaciones sociales.

\section{CONSIDERACIONES FINALES}

Quisiera concluir con una serie de reflexiones en tres direcciones. En primer lugar, cómo vivieron o, mejor dicho, qué beneficios pecuniarios obtuvieron. Se trataba de personas con recursos medios. No eran potentados, pero tampoco desarrapados. Su posición social era, aunque holgada, bastante discreta: "los pocos que aún viven, gozan de buen capital”, señaló un periodista que atestiguó el estilo de vida de algunos que otrora participaron en las estafas a las compañías de seguros. ${ }^{55}$ Incluso antes de obtener pingües ganancias, Balmori -a quien nunca aprehendieron ni se supo más después de su retorno a Españahabía sido propietario de una tienda de abarrotes, mientras que Emeterio Celorio era propietario del salón cantina La Universal sobre la céntrica avenida 16 de Septiembre. ${ }^{56}$

Amén de su importancia, esta condición social media no explica a cabalidad las motivaciones de los defraudadores. Acaso algunos sí escalaron socialmente, pero los intereses materiales,

\footnotetext{
54 “Los peleles: burlas al público”, El Popular (18 jun. 1902).

${ }_{55}$ Mellado, Belén, p. 152.

${ }^{56}$ Revista Española (1o ene. 1923).
} 
en este caso, se antojan insuficientes. Por otra parte, desconocemos rasgos ideológicos precisos para pensar que hubiera un rechazo al capital extranjero -finalmente eligieron varias compañías foráneas y, muy particularmente, de origen estadounidense- pero ninguna prueba sugiere un conflicto xenófobo ni sentimientos antiyanquis. Lo cierto es que el hecho de engañar parecía producir satisfacciones en un orden menos tangible.

Lamentablemente, los divanes son poco afables para la metodología histórica. Por este motivo, el segundo argumento tocaría a la profesionalización de la delincuencia. La esfera pública sensacionalista informaba sobre la presencia de "criminales de alta escuela”, participando de un fenómeno con manifestaciones culturales amplias en la conceptualización del hampa, como sugiere la circulación del binomio "bajos fondos" en los imaginarios de diversas latitudes. ${ }^{57}$ En este caso, la conexión deja de ser mera interpretación: uno de los peleles reincidiría, ya sexagenario, figurando en uno de los episodios más conspicuos en la historia de la estafa en México. Años más tarde, Francisco Cerezo fue parte de la Banda Internacional de Estafadores, cuyos miembros fueron capturados en 1926 y confinados un par de años en la colonia penal de las Islas Marías. Cumplieron su condena, pero falsificar y estafar era menos una desviación de la ley penal que una subespecie de oficio, pues reincidió durante la década de 1930. Esto aportó mayor densidad al caso, pues incluso los penalistas opinaron que debía reformarse el código para sancionar con severidad el fraude y la estafa.

Por último, estos profesionales del delito tuvieron un irrecusable componente organizativo. Con suficiente razón podría decirse que la época de los bandidos había exhibido el potencial de asociarse para obtener recursos y mantener impunidad. Sin embargo, hay un rasgo distinto en la organización de delitos por su carácter urbano e, incluso, algunos aceptarían

57 Kalifa, Los bajos fondos. 
en denominarlo moderno por burlar negocios que crecieron gracias al capitalismo financiero. ¿Qué tan lejos estuvo de ser una empresa criminal? Mínimamente, hubo un autor intelectual que fue Balmori, quien maquinó el primer golpe y aconsejó a Madiedo. También con liderazgo, aunque con un carácter más ejecutivo o pragmático, éste repetiría hasta seis veces los golpes contra las compañías de seguros y operó como una suerte de productor del guión, consiguió al médico que a cambio de unos pesos emitió los certificados de defunción y convenció al resto de los integrantes de contratar pólizas. Como empresa nueva, fracasó por un descuido. Excluir de la organización al artesano que fabricó uno de los muñecos y cuyo oficio fue explotado para engañar a los vecinos, quienes de reojo consensuaron que dentro del féretro había un cadáver. Las muestras del talento de este falsificador sólo pueden constatarse en los grabados publicados por Jueves de El Mundo.

Si acaso existió, la complicidad con autoridades no dejó rastros más allá de la participación de un agente de la policía Reservada, mientras que la responsabilidad del agente de seguros se mantuvo en las declaraciones de indiciados y de los abogados defensores. Esos tres elementos mencionados -es decir, condición social media, profesionalización del delito y organización del crimen- son suficientes para reconocer la importancia de los peleles en la historia de la estafa. Si bien en ciernes, un enfoque global sería todavía forzado en comparación con otros casos. Es verdad que su carácter de inmigrantes, nada extraño en plena era del flujo masivo de población europea a América, o bien sus propias víctimas, esto es, compañías de seguros, tendrían una estrecha relación con la expansión del capitalismo financiero. Las conexiones son igual de significativas que la falta de ellas: bastó que Balmori regresara a su país para eludir la justicia. A diferencia de otros contextos en que las policías colaboraban para perseguir a los delincuentes que viajaban para eludir la ley, las autoridades mexicanas poco habían 
extendido una red de cooperación transatlántica, acaso apenas transfronteriza con Estados Unidos. Finalmente, y por el lado de los criminales, es dudoso que mantuvieran conexiones de ida y vuelta con otros polos, como se observaría en episodios de estafa posteriores.

\section{SIGLAS Y REFERENCIAS}

AGN, TSJDF Archivo General de la Nación, Tribunal Superior de Justicia del Distrito Federal, Ciudad de México, México.

CEHM-CARSO Centro de Estudios en Historia de México CARSO, Ciudad de México, México.

ASCJN Archivo de la Suprema Corte de Justicia de la Nación, México.

CEIPJDF Cuadros estadísticos e informe del procurador de Justicia concernientes a la criminalidad en el Distrito Federal y territorios, México.

DJ Diario de Jurisprudencia, México.

DOF Diario Oficial de la Federación, México.

LIPEEF Ley de ingresos y presupuesto de egresos del erario federal, México.

Agostoni, Claudia y Elisa Speckman (eds.), De normas y transgresiones. Enfermedad y crimen en América Latina, 1850-1950, México, Universidad Nacional Autónoma de México, 2005.

Ariès, Philippe, L'homme devant la mort, París, Le Seuil, 1977.

Buffington, Robert, Criminal and Citizen in Modern Mexico, Lincoln, University of Nebraska, 2000.

Buley, R. Carlyle, The Equitable Life Assurance Society of the United States: One Hundred Anniversary History, 1859-1959, Nueva York, AppletonCentury-Crofts [1959].

Buley, R. Carlyle, The American Life Convention, 1906-1952: A Study in the History of Life Insurance, Nueva York, Appleton Century-Crofsts, 1953, 2 volúmenes.

Caimari, Lila y Máximo Sozzo (coords.), Historia de la cuestión criminal en América Latina, Rosario, Prohistoria, 2017. 
Clough, Shepard B., A Century of American Life Insurance: A History of the Mutual Life Insurance Company of New York, 1843-1943, Nueva York, Columbia University Press, 1946.

Driel, Hugo van, "Financial Fraud, Scandals, and Regulation: A Conceptual Framework and Literature Review", en Business History (2018), pp. 1-41.

Dublán, Manuel y José María Lozano (comps.), Legislación mexicana o colección completa de las disposiciones legislativas, México, Imprenta del Partido Liberal, 1876-1912.

Figueroa Doménech, J., Guia general descriptiva de la República Mexicana, México, Barcelona, R. de S. N. Araluce, 1899.

Galeano, Diego, "Un artista del delito: circulación de dinero falso entre el Río de la Plata y el Brasil, 1899-1911”, en CaIMARi y Sozzo (coords.), 2017, pp. 195-233.

Kalifa, Dominique, Los bajos fondos. Historia de un imaginario, México, Instituto Mora, 2018.

Knepper, Paul y Anja Johansen (eds.), The Oxford Handbook of the History of Crime and Criminal Justice, Oxford, Oxford University Press, 2016.

Levi, Michael, "Financial Crimes in Comparative Perspective", en Schlomo Giora, Paul Knepper y Martin Kett (eds.), International Handbook of Criminology, Nueva York, CRC Press, 2010, pp. 391-342.

LidA, Clara E., Inmigración y exilio. Reflexiones sobre el caso español, Madrid, Siglo Veintiuno Editores, 1997.

MANes, Alfred, "Insurance Crimes”, en Journal of Criminal Law and Criminology, 35: 1 (1944-1945), pp. 34-42.

Mellado, Guillermo, Belén por dentro y por fuera, México, Cuadernos Criminalia, 1959.

Merkel, Philip L., “Going National: The Life Insurance Industry’s Campaign for Federal Regulation after the Civil War”, en The Business History Review, 65: 3 (1993), pp. 528-553.

Miller, William (ed.), Men in Business: Essays in the History of Entrepreneurship, Cambridge, Harvard University Press, 1952. 
North, Douglas, "Capital Accumulation in Life Insurance between the Civil War and the Investigation of 1905”, en Miller (ed.), 1952, pp. 209-253.

Palma Alvarado, Daniel, Ladrones: historia social y cultura del robo en Chile, 1870-1920, Santiago, LOM Editores, 2011.

Payno, Joaquín, Amparo Samuel Karsenty contra actos del C. Juez $2^{\circ}$ de instrucción, México, Imprenta y Litografía La Europea, 1905.

Pearson, Robin (ed.), The Development of International Insurance, Londres, Pickering \& Chatto, 2010.

Piccato, Pablo, City of Suspects: Crime in Mexico City, 1900-1931, Durham, Duke University Press, 2001.

Piccato, Pablo, "De otarios y timadores: guión para una estafa y crítica de la moralidad callejera en la ciudad de México a fines del Porfiriato", en AgosTONI y Speckman (eds.), 2005, pp. 255-286.

Ransom, Roger L. y Richard Sutch, "Tontine Insurance and the Armstrong Investigation: A Case of Stifled Innovation, 1868-1905”, en Journal of Economic History, 47: 2 (1987), pp. 379-390.

Riguzzi, Paolo y Patricia de los Ríos, Las relaciones México-Estados Unidos, 1756-2010, México, Universidad Nacional Autónoma de México, Centro de Investigaciones sobre América del Norte, Secretaría de Relaciones Exteriores, 2012.

Sánchez-Albornoz, Nicolás, La población de América Latina desde los tiempos precolombinos hasta al año 2000, Madrid, Alianza Editorial, 1973.

SHORE, Heather, "A Brief History of the Underworld and Organized Crime, c. 1750-1950”, en KNepper y Johansen (eds.), 2016, pp. 170-191.

Speckman, Elisa, Crimen y castigo. Legislación penal, interpretaciones de la criminalidad y administración de justicia (Ciudad de México 1872-1910), México, El Colegio de México, Universidad Nacional Autónoma de México, 2002.

Van Leeuwen, Marco D., Mutual Insurance, 1550-2015. From Guild Welfare and Friendly Societies to Contemporary Micro-Insurers, Londres, Palgrave McMillan, 2016. 
Zelizer, Viviana A., "Human Values and the Market: The Case of Life Insurance and Death in 19th-Century America", en American Journal of Sociology, 84: 3 (1974), pp. 591-610. 